\title{
Cluster Analysis on Longitudinal Data of Patients with Adult-Onset Asthma
}

Pinja Ilmarinen, $\mathrm{PhD}^{\mathrm{a}}$, Leena E. Tuomisto, MD, PhD ${ }^{a}$, Onni Niemelä, MD, PhD ${ }^{\mathrm{b}, \mathrm{c}}$, Minna Tommola, MD ${ }^{\mathrm{a}}$, Jussi Haanpää, MSc ${ }^{d}$, and Hannu Kankaanranta, MD, PhD ${ }^{\mathrm{a}, \mathrm{e}}$ Seinäjoki and Tampere, Finland

What is already known about this topic? Many phenotypes of asthma have been identified in previous cluster analyses, mostly on the basis of cross-sectional data with limited inclusion of patients. Some studies have provided short-term 1- to 3-year prognosis for the phenotypes.

What does this article add to our knowledge? This is the first study that reports long-term 12-year prognosis for clusters of adult-onset asthma starting from diagnosis. We report different disease prognoses for smoking, obesity-related, female, atopic, and nonrhinitic asthma.

How does this study impact current management guidelines? Information on long-term outcome of asthma can be used to inform and motivate patients. We show the poorest outcome and the most unmet needs in the therapy of smoking and obesity-related asthma, suggesting need for special guidance.

BACKGROUND: Previous cluster analyses on asthma are based on cross-sectional data.

OBJECTIVE: To identify phenotypes of adult-onset asthma by using data from baseline (diagnostic) and 12-year follow-up visits.

METHODS: The Seinäjoki Adult Asthma Study is a 12-year follow-up study of patients with new-onset adult asthma. K-means cluster analysis was performed by using variables from baseline and follow-up visits on 171 patients to identify phenotypes.

RESULTS: Five clusters were identified. Patients in cluster $1(n=38)$ were predominantly nonatopic males with moderate smoking history at baseline. At follow-up, $40 \%$ of these patients had developed persistent obstruction but the number of patients with uncontrolled asthma (5\%) and rhinitis (10\%) was the lowest. Cluster $2(\mathrm{n}=19)$ was characterized by older men with heavy smoking history, poor lung function, and persistent obstruction at baseline. At follow-up, these patients were mostly uncontrolled (84\%) despite daily use of inhaled corticosteroid (ICS) with add-on therapy. Cluster $3(n=50)$ consisted mostly of nonsmoking females with good lung function at diagnosis/ follow-up and well-controlled/partially controlled asthma at follow-up. Cluster $4(n=25)$ had obese and symptomatic patients at baseline/follow-up. At follow-up, these patients had several comorbidities ( $40 \%$ psychiatric disease) and were treated daily with ICS and add-on therapy. Patients in cluster 5 ( $n=39)$ were mostly atopic and had the earliest onset of asthma, the highest blood eosinophils, and $\mathrm{FEV}_{1}$ reversibility at diagnosis. At follow-up, these patients used the lowest ICS dose but $56 \%$ were well controlled.

CONCLUSIONS: Results can be used to predict outcomes of patients with adult-onset asthma and to aid in development of

\footnotetext{
a'Department of Respiratory Medicine, Seinäjoki Central Hospital, Seinäjoki, Finland bepartment of Laboratory Medicine, Seinäjoki Central Hospital, Seinäjoki, Finland ${ }^{c}$ University of Tampere, Tampere, Finland

${ }^{\mathrm{d}}$ Department of Clinical Physiology, Seinäjoki Central Hospital, Seinäjoki, Finland ${ }^{\mathrm{e}}$ Department of Respiratory Medicine, University of Tampere, Tampere, Finland This study was supported by the Finnish Anti-Tuberculosis Association Foundation (Helsinki, Finland), the Tampere Tuberculosis Foundation (Tampere, Finland), the Jalmari and Rauha Ahokas Foundation (Helsinki, Finland), the Research Foundation of the Pulmonary Diseases (Helsinki, Finland), the Competitive State Research Financing of the Expert Responsibility Area of Tampere University Hospital (Tampere, Finland), and the Medical Research Fund of Seinäjoki Central Hospital (Seinäjoki, Finland). None of the sponsors had any involvement in the planning and execution of this study or in the writing of this article.

Conflicts of interest: P. Ilmarinen has received lecture fees from MundiPharma. L. E. Tuomisto has received lecture fees from Mundipharma and has received travel support from Takeda, Chiesi, and Orion. M. Tommola has received lecture fees from AstraZeneca and GlaxoSmithKline. H. Kankaanranta has received lecture and consultancy fees and travel support from Almirall,
}

AstraZeneca, and Boehringer Ingelheim; has received consultancy fees from Chiesi Pharma $\mathrm{AB}$; has received lecture and consultancy fees from GlaxoSmithKline, Leiras-Takesa, and Novartis; has received lecture fees from MSD, Mundipharma, Medith, Resmed Finland, and Orion Pharma; has received travel support from Intermune; and has received consultancy fees from Roche. The rest of the authors declare that they have no relevant conflicts of interest.

Received for publication October 25, 2016; revised January 3, 2017; accepted for publication January 31, 2017.

Available online April 25, 2017.

Corresponding author: Pinja Ilmarinen, PhD, Department of Respiratory Medicine, Seinäjoki Central Hospital, Hanneksenrinne 7, Seinäjoki 60220, Finland. E-mail: pinja.ilmarinen@epshp.fi.

2213-2198

(C) 2017 The Authors. Published by Elsevier Inc. on behalf of the American Academy of Allergy, Asthma \& Immunology. This is an open access article under the CC BY-NC-ND license (http://creativecommons.org/licenses/by-nc-nd/4.0/).

http://dx.doi.org/10.1016/j.jaip.2017.01.027 


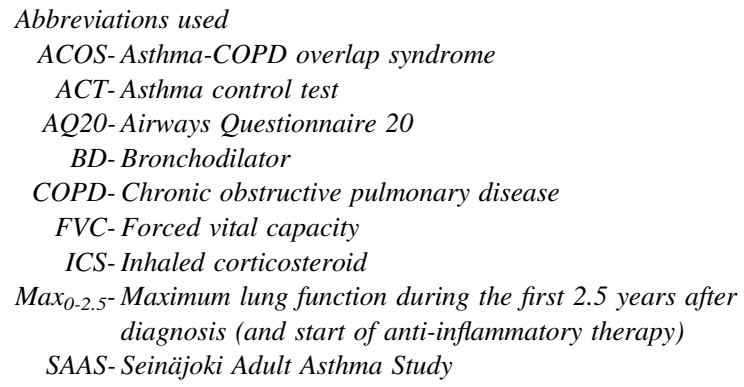

personalized therapy (NCT02733016 at ClinicalTrials. gov). (C) 2017 The Authors. Published by Elsevier Inc. on behalf of the American Academy of Allergy, Asthma \& Immunology. This is an open access article under the CC BYNC-ND license (http://creativecommons.org/licenses/by-ncnd/4.0/). (J Allergy Clin Immunol Pract 2017;5:967-78)

Key words: Asthma; Adult-onset; Late-onset; Cluster analysis; Phenotypes; Follow-up; Longitudinal; Smoking; Obesity; Early-onset

Adult- or late-onset asthma has been suggested to be a distinctive phenotype of asthma. ${ }^{1,2}$ Patients with adult-onset asthma have lesser allergic processes, lower lung function despite shorter duration of disease, and more often a pronounced eosinophilic inflammation without evidence of $\mathrm{T}_{\mathrm{H}} 2$-associated inflammation when compared with patients with childhoodonset asthma. ${ }^{1}$ These findings suggest that adult-onset asthma is more heterogeneous when compared with childhood-onset asthma. In previous studies, subphenotypes of adult-onset asthma such as eosinophil-predominant, mild to moderate well-controlled, obesity-related, smoking, and severe obstructive asthma have been proposed.,

To identify phenotypes of asthma, unsupervised hierarchical cluster analyses have been carried out. However, the cluster analyses have mostly been based on cross-sectional data on patients with mixed duration of asthma. ${ }^{2,4-6}$ Asthma is known as a disease with a high degree of variability, making one time point a fragile basis for cluster analysis. Furthermore, no information on the diagnostic phase has been included in the previous analyses. In addition, many previous analyses have clustered patients with severe asthma, ${ }^{7,8}$ leaving milder forms with less attention. Some studies have involved short follow-ups (1-3 years)..$^{6,7,9,10}$ In a previous prospective longitudinal analysis of severe asthma, the clusters did not show cluster-specific disease courses regarding outcome of asthma, suggesting a potential limitation in the way of performing current cluster analyses. ${ }^{9}$ In addition to the natural disease variability, many factors such as therapy, lifestyle, and comorbidities may modify the disease course. Reliability of the results of a cluster analysis would be increased by including clinical data from several time points of the disease follow-up into the analysis.

Here, we used a long-term follow-up approach to construct phenotypes of adult-onset asthma by carrying out a cluster analysis with inclusion of variables from diagnosis to a 12 -year follow-up visit. This approach provides novel insights into the phenotypes of asthma with prognostic significance.

\section{METHODS \\ Patients and study design}

The present study was part of the Seinäjoki Adult Asthma Study (SAAS), which is a prospective, single-center (Seinäjoki Central Hospital, Seinäjoki, Finland), 12-year follow-up study of a cohort of consecutive white patients having new-onset asthma diagnosed at adult age ( $\geq 15$ years). SAAS has been registered on ClinicalTrials.gov with ID NCT02733016. Institutional permissions (TU1114 and LET) were obtained and the participants gave written informed consent to the study protocol approved by the Ethics Committee of Tampere University Hospital, Tampere, Finland (R12122). The protocol, inclusion and exclusion criteria, and the background data of SAAS have been published elsewhere. ${ }^{11}$ Briefly, asthma was diagnosed by a specialized respiratory physician during the period 1999 to 2002 on the basis of typical clinical symptoms and confirmed by objective lung function measurements. ${ }^{11,12}$ The main diagnostic features of asthma in each cluster are presented in Table E1 in this article's Online Repository at www.jaci-inpractice.org. Smokers and patients with comorbidities were not excluded. After diagnosis, the patients were treated and monitored in specialized or primary care as required. The total cohort consisted of 257 patients and 203 patients completed the follow-up visit (mean follow-up time, 12.2 years; range, 10.8-13.9 years). At 12-year follow-up visit, asthma status and disease control, comorbidities, and medication were evaluated using structured questionnaires and lung function was measured. Data on asthma-related visits to health care and hospitalizations were also collected from primary care, occupational health care, private clinics, and hospitals. After excluding those with missing data, 171 patients with adult-onset asthma remained in the cohort for cluster analysis (Figure 1).

\section{Lung function, comorbidities, inflammatory parameters, and other clinical measurements}

Lung function was measured with a spirometer according to international recommendations. ${ }^{13}$ The following were the lung function measurement points: (1) baseline (time of asthma diagnosis), (2) the maximum prebronchodilator $\mathrm{FEV}_{1}$ (Pre-BD FEV F $_{1}$ ) during the first 2.5 years after diagnosis $\left(\mathrm{Max}_{0-2.5}\right)$ (and after start of anti-inflammatory therapy), and (3) 12-year follow-up. ${ }^{14}$ Detailed information on determination of lung function, inflammatory parameters, and comorbidities can be found in this article's Online Repository at www.jaci-inpractice.org. Asthma control was assessed according to the Global Initiative for Asthma 2010 report. ${ }^{15}$ Patients filled out the Airways Questionnaire 20 (AQ20) at baseline visit and AQ20 and asthma control test (ACT) questionnaires at the followup visit. The AQ20 is a short and simple well-validated questionnaire to measure and quantify disturbances in the airway-specific quality of life. ${ }^{16}$ ACT is a widely used patient self-administered tool for identifying those with poorly controlled asthma. ${ }^{17}$

\section{Variable selection}

Input variables for the cluster analysis were selected on the basis of factor analysis (see Table E2 in this article's Online Repository at www.jaci-inpractice.org). Basic and clinical variables included in factor analysis were chosen to cover as wide a range as possible from diagnosis to 12-year follow-up visit and are further discussed in this article's Online Repository at www.jaci-inpractice.org.

\section{Cluster analysis and discriminant analysis}

Cluster analysis was carried out by using a 2 -step process. First, Ward hierarchical cluster analysis was performed for preevaluation of 


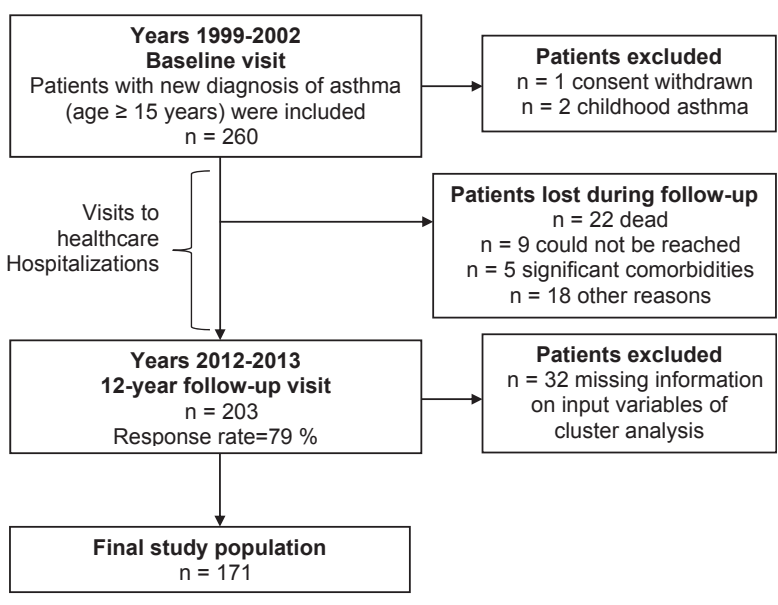

FIGURE 1. Flow chart of the study.

the number of clusters. Then, $\mathrm{K}$-means analysis was carried out by using the prespecified number of clusters (5). Stepwise discriminant analysis was performed to identify variables discriminating between the prespecified clusters. Statistically significant results were expected for most of the comparisons because the objective of the cluster analysis was to differentiate the participants into distinct phenotypes of adult-onset asthma.

\section{Other statistical analyses}

Continuous data are expressed as mean $\pm S D$ or median and interquartile range. Group comparisons were performed by 1-way analysis of variance with the Tukey post hoc test, the KruskalWallis test, or the chi-square test. Statistical analyses were performed by using SPSS software, version 22 (IBM Corporation, Armonk, NY) and MATLAB, version 8.6 (Mathworks, Natick, Mass).

\section{RESULTS}

\section{Patients' characteristics}

Characteristics of the total cohort at baseline and follow-up are presented in Table E3 in this article's Online Repository at www. jaci-inpractice.org. Patients were mostly females (58.5\%) and nonatopic $(63.5 \%)$, with age at asthma onset ranging from 15 to 77 years. At diagnosis, most patients were steroid-naive. At the 12-year follow-up point, $78.9 \%$ were daily users of inhaled corticosteroid (ICS) and 50.9\% were daily users of ICS and add-on medication.

\section{Cluster analysis}

By performing Ward hierarchical and K-means cluster analyses, 5 clusters were identified. The basic characteristics of these clusters are shown in Figure 2. Cluster 1 was characterized by low prevalence $(10.5 \%)$ of rhinitis (nonrhinitic asthma), whereas cluster 2 had the highest smoking history (smoking asthma). Cluster 3 consisted mainly (98\%) of women (female asthma), and most patients in cluster 4 were obese from diagnosis to 12-year follow-up visit (obesity-related asthma). Cluster 5 mostly included atopic patients with the earliest onset of asthma (earlyonset atopic adult asthma). Basic and clinical characteristics of the clusters at baseline and at follow-up are presented in Tables I-IV. There were no major differences in the main diagnostic features between groups (see Table E1 in this article's Online Repository at www.jaci-inpractice.org).

Cluster 1: Nonrhinitic asthma. Cluster 1 ( $\mathrm{n}=38$ [22.2\%]) was characterized by lack of rhinitis, male predominance $(60.5 \%)$, onset of asthma at middle age, and second highest smoking history (Figure 2). Proportion of patients with permanent bronchial obstruction (post-BD $\mathrm{FEV}_{1} /$ forced vital capacity [FVC] $<0.7$ ) increased from $10.8 \%$ to $39.5 \%$ from diagnosis to 12 -year follow-up visit. This cluster also showed the highest weight gain, with the proportion of obese patients increasing from $18.4 \%$ to $39.5 \%$. Asthma was uncontrolled in only $5.3 \%$ of the patients, even though most (55.9\%) were treated with low-dose ICS or no daily ICS (Table I). Cluster 1 showed moderate loss of $\mathrm{FEV}_{1}$ during the follow-up and the lowest use of health care (Figures 3 and 4). Patients had 1 comorbidity on average at the 12-year follow-up visit, the most prevalent being chronic obstructive pulmonary disease (COPD) and hypertension (Table IV).

Cluster 2: Smoking asthma. Cluster 2 was the smallest cluster $(\mathrm{n}=19[11.1 \%])$ and was predominated by older males. Almost $80 \%$ of patients had smoking history and $44.4 \%$ showed bronchial obstruction at diagnosis and could be characterized as having asthma-COPD overlap syndrome (ACOS). ${ }^{18}$ However, the smoking cluster did not differ from other clusters on the basis of diffusing capacity. The patients had poor lung function, high symptoms, and uncontrolled asthma despite $94.7 \%$ being under daily ICS therapy, $73.4 \%$ with moderate-to high-dose ICS, and $78.9 \%$ with long-acting $\beta_{2}$ agonist at follow-up. Even though lung function significantly improved after start of therapy, the annual decline in $\mathrm{FEV}_{1}$ was steep $(78 \mathrm{~mL}$ on average) from the maximum point of lung function to the 12-year follow-up visit (Figure 4; Table II). This was the only group with no decrease in blood eosinophils or symptoms from diagnosis to follow-up (Figure 4). The patients had 3 comorbidities on average (Table IV) and frequent health care use (Figure 3). Of the patients, 36.8\% had been hospitalized for asthma (Figure 3, B) and this cluster accounted for $35.8 \%$ of all hospital treatment periods.

Cluster 3: Female asthma. This group was the largest $(\mathrm{n}=$ 50 [29.2\%]) and consisted of women with a wide range in the age of asthma onset. Cluster 3 contained more (44\%) patients with normal weight (body mass index $<25$ ) compared with other clusters and showed the lowest smoking history. Forty percent reported being symptomatic already during childhood even though they were not diagnosed as having asthma. Pre-BD FEV was normal ( $>80 \%$ predicted) in $78 \%$ at diagnosis and in $90 \%$ at follow-up, and the annual decline in $\mathrm{FEV}_{1}$ was the lowest (31 $\mathrm{mL}$ ). Blood eosinophils were the second highest and the AQ20 symptom score was at a rather moderate level of 6 out of 20 at diagnosis, and both reduced during the follow-up (Figure 4). Even though lung function measured by spirometry and inflammation were within normal range and $78 \%$ were undergoing ICS treatment at the 12-year follow-up visit, $64 \%$ of the patients were partially controlled or uncontrolled and health care use was relatively high (Table I; Figure 3). Female cluster accounted for $29.0 \%$ of all asthma-related visits.

Cluster 4: Obesity-related asthma. This cluster $(\mathrm{n}=25$ [14.6\%]) mostly contained nonatopic females with the oldest age 
A
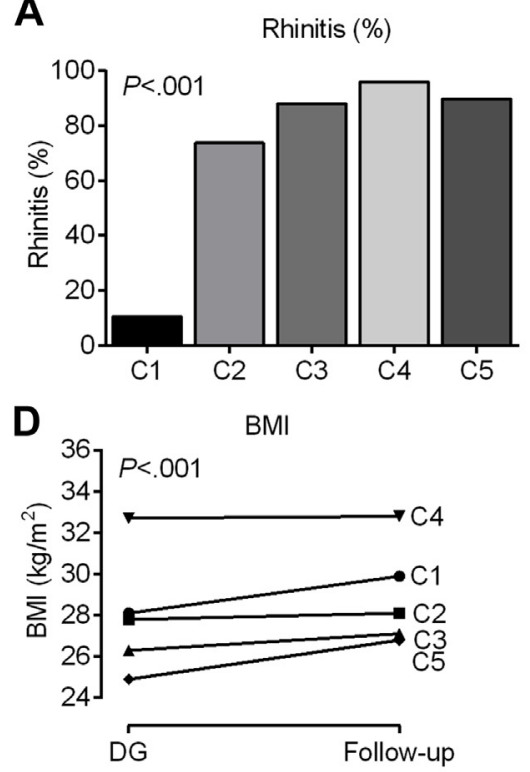

B

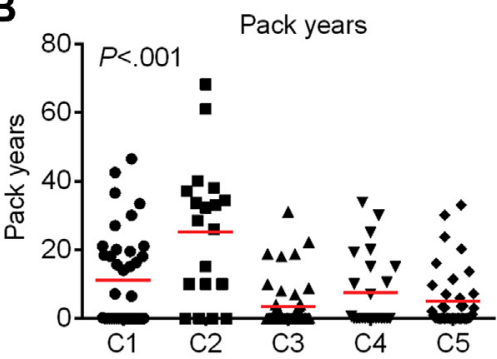

E

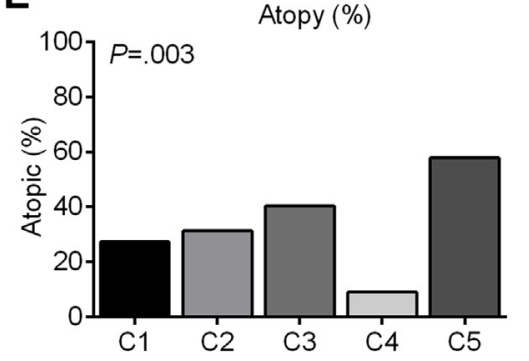

C

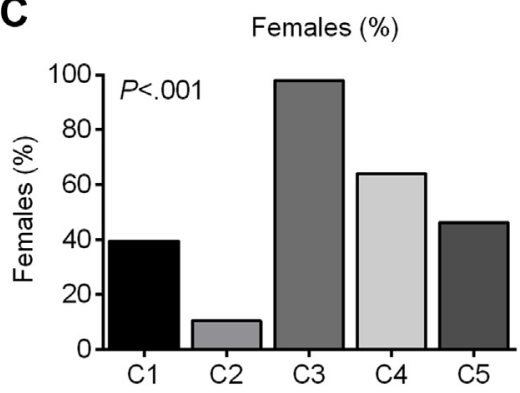

$\mathbf{F}$

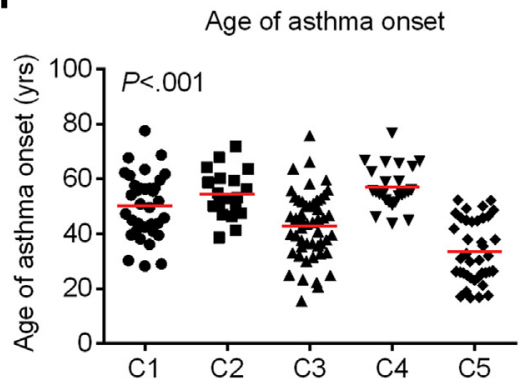

FIGURE 2. Basic characteristics of clusters. In A-F, $C 1$ to $C 5$ refer to the cluster numbers. Overall $P$ values are shown. In $B$ and $F$, the red lines shown are means. In $\mathbf{D}$, means are shown. $B M I$, Body mass index; $D G$, diagnosis.

of asthma onset. On average, patients were obese from diagnosis to the 12-year follow-up point without gaining more weight during this time. The patients were multimorbid at follow-up (Table IV), with the most prevalent comorbidities being hypertension, diabetes, and psychiatric diseases. Asthma was uncontrolled in $48 \%$ of the patients at follow-up even though $92 \%$ were undergoing ICS treatment, 50\% used high-dose ICS, and $72 \%$ were on add-on medication (Table I). At diagnosis, $44 \%$ showed pre-BD $\mathrm{FEV}_{1}$ of more than $80 \%$ predicted. Lung function improved on start of therapy and remained relatively stable throughout follow-up (Figure $4, A$ ). Respiratory symptoms, use of oral steroids, and health care use were all at high levels (Figures 3 and 4).

Cluster 5: Early-onset atopic adult asthma. This group was the second largest $(n=39$ [22.8\%]) and consisted of the youngest patients with mean age of asthma onset at $33 \pm 11$ years. Almost half had suffered from respiratory symptoms during childhood, 59\% were atopic, and 90\% had nonallergic or allergic rhinitis (Table I). Of this cluster, 59\% showed preBD $\mathrm{FEV}_{1}$ of more than $80 \%$ at diagnosis and $84 \%$ could be reversed to $\mathrm{FEV}_{1}$ of more than $80 \%$ predicted by $\mathrm{BD}$. Reversibility was in general the highest. Lung function initially showed a good response to steroids, even though the loss of lung function after the maximum point was also the second steepest. At diagnosis, these patients showed the highest blood eosinophils (Table III), which reduced until the 12-year followup visit (Figure 4). Asthma was controlled in 56\% of the subjects and use of medication was the lowest, because $56 \%$ were using low-dose ICS or no medication and only $17.9 \%$ were treated by long-acting $\beta_{2}$ agonist (Table I). Use of steroid bursts was infrequent and use of health care was among the lowest (Figure 3).

\section{Validation}

For validation, we carried out $\mathrm{K}$-means algorithm 10 times by the leave-one-out method to ensure stability and repeatability of the model. This method showed $94.4 \%$ repeatability.

\section{Discriminant analysis}

By using a stepwise method of discriminant analysis, 12 out of 17 variables were found to significantly discriminate between the clusters: the diagnostic variables were post-BD FEV 1 FVC, $\mathrm{FEV}_{1}$ reversibility, and maximal change in $\mathrm{FEV}_{1}$ (from diagnosis to $\mathrm{Max}_{0-2.5}$ ), whereas the follow-up variables included rhinitis, number of drugs in use to treat comorbidities, pre-BD $\mathrm{FEV}_{1}$, pack-years, body mass index, limitation of activities (none/any), and basic variables of sex, age at asthma onset, and symptoms of asthma for less than 16 years, of which rhinitis, post-BD $\mathrm{FEV}_{1}$ / FVC, number of drugs in use to treat comorbidities, and sex were found to be the strongest discriminating variables. Duration of symptoms before diagnosis, blood eosinophils and neutrophils, reversibility at follow-up, and ACT score were not found as statistically significant discriminants. The percentage of correct classification on the basis of the 12 discriminating variables was 94.7\% (data not shown).

\section{DISCUSSION}

In this study, we identified phenotypes of adult-onset asthma by using longitudinal data and basic and clinical variables ranging from the diagnostic phase to the 12-year follow-up visit. Our cohort included smokers and patients with comorbidities. The following 5 phenotypes were identified: (1) nonrhinitic controlled to partially controlled asthma with low use of medication and health care; (2) smoking asthma or ACOS with poor lung function, high symptoms, and high use of medication and health care; (3) female asthma with normal clinical parameters 


\begin{tabular}{|c|c|c|c|c|c|c|c|c|c|c|c|c|}
\hline \multirow[t]{2}{*}{ Features } & \multicolumn{2}{|c|}{$\begin{array}{c}\text { Cluster 1: } \\
\text { nonrhinitic }(n=38)\end{array}$} & \multicolumn{2}{|c|}{$\begin{array}{c}\text { Cluster 2: } \\
\text { smoking }(n=19)\end{array}$} & \multicolumn{2}{|c|}{$\begin{array}{c}\text { Cluster 3: } \\
\text { female }(n=50)\end{array}$} & \multicolumn{2}{|c|}{$\begin{array}{c}\text { Cluster 4: } \\
\text { obese }(n=25)\end{array}$} & \multicolumn{2}{|c|}{$\begin{array}{l}\text { Cluster 5: } \\
\text { atopic }(n=39)\end{array}$} & \multirow{2}{*}{$\begin{array}{c}P \text { value } \\
\text { between } \\
\text { clusters }\end{array}$} & \multirow{2}{*}{$\begin{array}{c}\begin{array}{c}P \text { value } \\
\text { between } \\
\text { clusters }\end{array} \\
\text { Follow-up }\end{array}$} \\
\hline & Baseline & Follow-up & Baseline & Follow-up & Baseline & Follow-up & Baseline & Follow-up & Baseline & Follow-up & & \\
\hline \multicolumn{13}{|c|}{ Demographic characteristics and anthopometrics } \\
\hline Females, n (\%) & $15(39.5)$ & & $2(10.5)^{*}$ & & $49(98) \dagger$ & & $16(64)$ & & $18(46.2)$ & & $<.001$ & \\
\hline Age $(y)$, mean $\pm S D$ & $50 \pm 12$ & $63 \pm 12$ & $55 \pm 9$ & $66 \pm 9$ & $43 \pm 12 \dagger$ & $55 \pm 12 \dagger$ & $57 \pm 8$ & $69 \pm 8$ & $33 \pm 11 \dagger$ & $45 \pm 11 \dagger$ & $<.001$ & $<.001$ \\
\hline $\begin{array}{l}\text { BMI }\left(\mathrm{kg} / \mathrm{m}^{2}\right) \text {, mean } \pm \\
\quad \text { SD }\end{array}$ & $28.1 \pm 5.5 \ddagger$ & $29.9 \pm 6.5$ & $27.8 \pm 4.0$ & $28.1 \pm 4.9$ & $26.3 \pm 4.3$ & $27.1 \pm 4.8$ & $32.7 \pm 5.2 \dagger$ & $32.8 \pm 5.3 \ddagger \S \|$ & $24.9 \pm 3.5$ & $26.8 \pm 3.9$ & $<.001$ & $<.001$ \\
\hline Obese (BMI > 30), n (\%) & $7(18.4)$ & $15(39.5)$ & $8(42.1) \ddagger$ & $7(36.8)$ & $7(14.0)$ & $13(26.0)$ & $17(68.0) \ddagger \| \uparrow$ & $18(72.0) \dagger$ & $4(10.3)$ & $9(23.1)$ & $<.001$ & .001 \\
\hline Smokers, $\mathrm{n}(\%)$ & $20(52.6)$ & $20(52.6)$ & $15(78.9) \|$ & 15 (78.9) || & $17(34)$ & $18(36)$ & $11(44)$ & $11(44)$ & $19(48.7)$ & $21(53.8)$ & .020 & .027 \\
\hline Current smoker, n (\%) & $7(18.4)$ & 7 (18.4) & $5(26.3)$ & $3(15.8)$ & $5(10)$ & $8(16)$ & $4(16)$ & 0 & $9(23.1)$ & $8(20.5)$ & .425 & .225 \\
\hline $\begin{array}{l}\text { Pack-years of smokers, } \\
\text { median (IQR) }\end{array}$ & $17(12-23) \|$ & $19(15-29) \ddagger \|$ & $29(14-34)^{*}+\|$ & $33(15-38) \ddagger$ & $5(2-10)$ & $6(2-18)$ & $15(10-20)$ & $15(10-25)$ & $4(3-7)$ & $6(3-15)$ & $<.001$ & $<.001$ \\
\hline $\begin{array}{l}\text { Symptoms of asthma } \\
\quad<16 \mathrm{y}, \mathrm{n}(\%)\end{array}$ & 0 & & $1(5.3)$ & & $20(40.0) * \llbracket$ & & $1(4.0)$ & & $19(48.7) * \S \rrbracket$ & & $<.001$ & \\
\hline $\begin{array}{l}\text { Symptoms of asthma } \\
\text { before diagnosis (mo), } \\
\text { median (IQR) }\end{array}$ & $18(9-60)$ & & $24(11-36)$ & & $12(9-36)$ & & $24(24-60) \ddagger \|$ & & $12(8-24)$ & & .008 & \\
\hline Atopic, n (\%) & $9(27.3)$ & ND & $5(31.3)$ & ND & $19(40.4)$ & ND & $2(9.1)$ & ND & $22(57.9)^{*}$ & ND & .003 & ND \\
\hline $\begin{array}{l}\text { No. of positive SPT, } \\
\text { median (IQR) }\end{array}$ & $0(0-1)$ & ND & $0(0-2)$ & ND & $0(0-2)^{*}$ & ND & $0(0-0)$ & ND & $1.5(0-3) * \S \rrbracket$ & ND & .001 & ND \\
\hline Rhinitis, n (\%) & ND & $4(10.5) \dagger$ & ND & $14(73.7)$ & ND & $44(88)$ & ND & $24(96)$ & ND & $35(89.7)$ & ND & $<.001$ \\
\hline \multicolumn{13}{|c|}{ Asthma control and quality of life } \\
\hline $\begin{array}{l}\text { AQ20 score, median } \\
\text { (IQR) }\end{array}$ & $5(3-7)$ & $2(1-4)$ & $8(5-10)$ & $8(5-11) \ddagger \| \Upsilon$ & $6(4-10)$ & $4(2-6)$ & $10(7-13) \ddagger \| \rrbracket$ & $7(4-9) \ddagger \Phi$ & $4(2-9)$ & $2(1-5)$ & $<.001$ & $<.001$ \\
\hline $\begin{array}{l}\text { ACT score, median } \\
\text { (IQR) }\end{array}$ & ND & $23(21-24)$ & ND & $20(13-21) \ddagger|| \uparrow$ & ND & $22(19-24)$ & ND & $19(15-22) \ddagger \rrbracket$ & ND & $23(21-25)$ & ND & $<.001$ \\
\hline ACT score $<20, \mathrm{n}(\%)$ & ND & $5(13.2)$ & ND & $9(47.4) \div \Phi$ & ND & $13(26.0)$ & ND & $15(60.0) \ddagger \|$ ฯ & ND & $5(12.8)$ & ND & $<.001$ \\
\hline Controlled, n (\%) & ND & $16(42.1)$ & ND & $2(10.5)$ & ND & $18(36)$ & ND & $4(16)$ & ND & $22(56.4) * \S$ & ND & $<.001$ \\
\hline Partly controlled, n (\%) & ND & $20(52.6) \S$ & ND & $1(5.3)$ & ND & $21(42) \S$ & ND & $9(36)$ & ND & $11(28.2)$ & ND & .007 \\
\hline Uncontrolled, n (\%) & ND & $2(5.3)$ & ND & $16(84.2) \ddagger \mid \|$ & ND & $11(22) \Phi$ & ND & 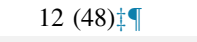 & ND & $6(15.4)$ & ND & $<.001$ \\
\hline \multicolumn{13}{|l|}{ Exacerbations } \\
\hline Oral steroids, n (\%)\# & & $2(5.4)$ & & $4(21.1)$ & & $6(12.2)$ & & $7(29.2)$ & & $2(5.1)$ & & .026 \\
\hline \multicolumn{13}{|l|}{ Treatment } \\
\hline Daily ICS user, n (\%)** & $1(2.6)$ & $27(71.1)$ & $1(5.3)$ & $18(94.7)$ & $6(12.2)$ & $39(78)$ & $2(8.0)$ & $23(92)$ & $2(5.1)$ & $28(71.8)$ & .479 & .089 \\
\hline $\begin{array}{l}\text { ICS dose, } \dagger \dagger \text { median } \\
\text { (IQR) }\end{array}$ & $900(800-1600)$ & $800(400-1000)$ & $800(700-1600)$ & $900(700-1400)$ & $800(400-1000)$ & $800(575-1000)$ & $1000(800-1400)$ & $1000(475-1525)$ & $800(800-1600)$ & $800(400-800)$ & .220 & .163 \\
\hline Low/none ICS dose, n (\%) & ND & $19(55.9)$ & ND & $4(26.7)$ & ND & $18(40)$ & ND & $6(30)$ & ND & $20(55.6)$ & ND & .109 \\
\hline Medium ICS dose, $\mathrm{n}(\%)$ & ND & 7 (20.6) & ND & $4(26.7)$ & ND & $11(24.4)$ & ND & $4(20)$ & ND & $11(30.6)$ & ND & .871 \\
\hline
\end{tabular}




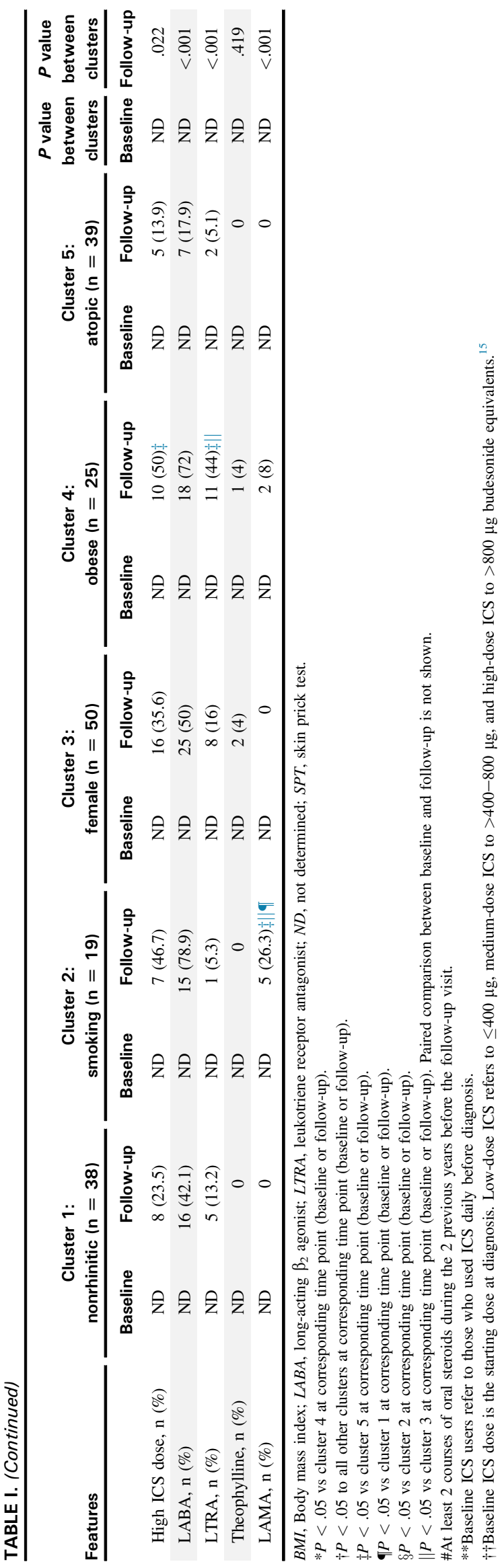

but relatively high use of health care; (4) obesity-related asthma with comorbidities, high symptoms, and high use of medication and health care; and (5) atopic well-controlled asthma with onset earlier in adulthood. Instead of characterizing phenotypes in one point of disease, we provide phenotypes based on 12-year follow-up data.

Our results show both similarities to and differences from those of previous cluster analyses based on cross-sectional data with mixed duration of asthma. Most previous analyses have excluded smokers or heavy smokers and only few have identified smoking asthma. ${ }^{6,19}$ Cluster A in the Cohort for Reality and Evolution of Adult Asthma in Korea (COREA) study ${ }^{6}$ resembled our smoking cluster in many respects. However, in our study, the smoking cluster showed an annual decline in $\mathrm{FEV}_{1}$ that was the steepest of all groups in contrast to the results of the COREA smoking cluster in 1-year follow-up. Many negative outcomes previously associated with smoking asthma were evident in our smoking cluster, including lower asthma-related quality of life (based on AQ20 score), frequent health care use, and severe/uncontrolled asthma. ${ }^{20-22}$ Even though the patients in the smoking cluster typically show irreversible airflow limitation and comorbidity profiles resembling that of COPD, normal average diffusing capacity in each cluster suggests that the main diagnosis is asthma and not emphysema. In addition, the diagnosis of asthma was made by a respiratory specialist and each patient fulfilled the diagnostic criteria of asthma including objective lung function measurements showing bronchial variability. This smoking group, although being the smallest one, was responsible for more than a third of all asthma-related hospitalizations, highlighting the significance of this group to health care costs. Obviously, much efforts should be focused on advising patients to stop smoking as early as possible, even before onset of asthma and before asthma turns from a milder form to difficult-to-treat smoking asthma with high burden for both individual and health care.

Obesity-related female-predominant asthma is a cluster identified in our study as well as in some previous studies, ${ }^{2,5,7,10}$ and our results add by providing data on prognosis of the long-term obesity. Our results on this cluster support previous findings indicating frequent symptoms and exacerbations, high use of health care, high medication, and a nonatopic, noneosinophilic disease characteristic. This cluster is also prone to create a high burden to health care, as evidenced by the most frequent use of oral corticosteroids and of health care services. To further add on previous studies, we found the highest number of comorbidities in the obese cluster and especially a high prevalence of psychiatric comorbidity (40\%). Consistently, in a previous study, the highest depression score was shown in the late-onset obese cluster in a cohort of severe asthma. ${ }^{7}$ However, interaction between obesity, psychiatric diseases, and asthma requires further studies. ${ }^{23,24}$ Recently, we showed that multimorbidity is associated with increased symptoms of asthma, which may be partly related to systemic inflammation in these patients. ${ }^{25}$ Systemic inflammation has been associated with high steroid dose in the treatment of adult-onset asthma. ${ }^{25}$ Therefore, multimorbidity and systemic inflammation may be relevant in turning asthma into symptomatic and steroid-resistant in obese patients. However, weight loss has resulted in improved symptoms, lung function, asthma control, and health status, ${ }^{23}$ suggesting that it would benefit this subgroup.

In addition to the obesity-related female-predominant group, we identified a nonobese cluster of females with good lung 
TABLE II. Lung function of clusters (mean \pm SD)

\begin{tabular}{|c|c|c|c|c|c|c|c|c|c|c|c|c|}
\hline \multirow[b]{2}{*}{ Characteristic } & \multicolumn{2}{|c|}{$\begin{array}{c}\text { Cluster 1: } \\
\text { nonrhinitic }(n=38) \\
\end{array}$} & \multicolumn{2}{|c|}{$\begin{array}{c}\text { Cluster 2: } \\
\text { smoking ( } n=19)\end{array}$} & \multicolumn{2}{|c|}{$\begin{array}{c}\text { Cluster } 3: \\
\text { female }(n=50)\end{array}$} & \multicolumn{2}{|c|}{$\begin{array}{c}\text { Cluster 4: } \\
\text { obese }(n=25)\end{array}$} & \multicolumn{2}{|c|}{$\begin{array}{l}\text { Cluster 5: } \\
\text { atopic }(n=39)\end{array}$} & \multirow{2}{*}{$\begin{array}{c}P \text { value } \\
\text { between } \\
\text { clusters } \\
\text { Baseline }\end{array}$} & \multirow{2}{*}{$\begin{array}{c}\begin{array}{c}P \text { value } \\
\text { between } \\
\text { clusters }\end{array} \\
\text { Follow-up }\end{array}$} \\
\hline & Baseline & Follow-up & Baseline & Follow-up & Baseline & Follow-up & Baseline & Follow-up & Baseline & Follow-up & & \\
\hline \multicolumn{13}{|l|}{ Lung function } \\
\hline Pre-BD FEV $1, \%$ ref & $82 \pm 15$ & $85 \pm 14^{*}$ & $53 \pm 18 \dagger$ & $63 \pm 19 \dagger$ & $90 \pm 12$ & $96 \pm 13$ & $78 \pm 13^{*}$ & $79 \pm 16^{*}$ & $81 \pm 14^{*}$ & $86 \pm 12 *$ & $<.001$ & $<.001$ \\
\hline Post-BD FEV ${ }_{1}, \%$ ref & $86 \pm 16$ & $89 \pm 14^{*}$ & $60 \pm 18^{\dagger}$ & $67 \pm 20 \dagger$ & $94 \pm 13$ & $98 \pm 13$ & $83 \pm 14^{*}$ & $81 \pm 16^{* \dagger}$ & $92 \pm 12$ & $92 \pm 12$ & $<.001$ & $<.001$ \\
\hline Pre-BD FVC, \%ref & $90 \pm 16$ & $97 \pm 14$ & $73 \pm 17 * \pm \S$ & $90 \pm 15^{*}$ & $95 \pm 12$ & $103 \pm 14$ & $84 \pm 13^{*}$ & $88 \pm 14^{*}$ & $93 \pm 15$ & $98 \pm 14$ & $<.001$ & $<.001$ \\
\hline Post-BD FVC, \%ref & $92 \pm 16$ & $100 \pm 16$ & $81 \pm 16^{*} \ddagger$ & $93 \pm 14$ & $96 \pm 13$ & $103 \pm 14$ & $86 \pm 12^{*} \ddagger$ & $90 \pm 14^{*}$ & $97 \pm 13$ & $99 \pm 14$ & $<.001$ & .007 \\
\hline $\begin{array}{l}\text { Pre-BD FEV } \mathrm{FEVC}_{1} / \mathrm{FV} \\
\quad \% \text { ref }\end{array}$ & $0.75 \pm 0.08^{*}$ & $0.71 \pm 0.08^{*}$ & $0.57 \pm 0.11 \dagger$ & $0.57 \pm 13 \dagger$ & $0.80 \pm 0.07$ & $0.76 \pm 0.05$ & $0.76 \pm 0.06$ & $0.72 \pm 0.10$ & $0.74 \pm 0.10^{*}$ & $0.72 \pm 0.07$ & $<.001$ & $<.001$ \\
\hline $\begin{array}{l}\text { Post-BD } \mathrm{FEV}_{1} / \mathrm{FVC}, \\
\text { \%ref }\end{array}$ & $0.77 \pm 0.07 *$ & $0.72 \pm 0.08^{*}$ & $0.58 \pm 0.12 \dagger$ & $0.58 \pm 0.14 \dagger$ & $0.83 \pm 0.07$ & $0.78 \pm 0.05$ & $0.78 \pm 0.08$ & $0.72 \pm 0.10^{*}$ & $0.81 \pm 0.08$ & $0.76 \pm 0.07$ & $<.001$ & $<.001$ \\
\hline $\mathrm{FEV}_{1}$ reversibility $(\mathrm{mL})$ & $166 \pm 137$ & $134 \pm 147^{*}$ & $267 \pm 251$ & $142 \pm 172^{*}$ & $139 \pm 142$ & $47 \pm 69$ & $144 \pm 211$ & $62 \pm 104$ & $407 \pm 204 * \S \|$ & $195 \pm 143 * \S \|$ & $<.001$ & $<.001$ \\
\hline $\begin{array}{c}\mathrm{FEV}_{1} \text { reversibility } \\
(\% \text { change })\end{array}$ & $5.6 \pm 5.3$ & $4.8 \pm 5.2^{*}$ & $15.0 \pm 16.4 * \mp \S \|$ & $6.8 \pm 7.7^{*}$ & $5.9 \pm 7.8$ & $1.8 \pm 2.8$ & $6.2 \pm 8.8$ & $3.2 \pm 5.3$ & $14.2 \pm 13.6 * \S \|$ & $6.6 \pm 5.6^{*}$ & $<.001$ & $<.001$ \\
\hline \multicolumn{13}{|l|}{ Diffusing capacity } \\
\hline $\mathrm{DL}_{\mathrm{CO}} / \mathrm{VA}$ (\%ref) & $104 \pm 17$ & $100 \pm 15$ & $94 \pm 21$ & $88 \pm 28$ & $100 \pm 20$ & $95 \pm 14$ & $99 \pm 18$ & $93 \pm 13$ & $107 \pm 16$ & $97 \pm 14$ & .155 & .107 \\
\hline \multicolumn{13}{|l|}{$\begin{array}{l}\text { Annual change in lung } \\
\text { function from } \\
\operatorname{Max}_{0-2.5} \text { to } \\
\text { follow-up } \Phi\end{array}$} \\
\hline$\Delta \mathrm{FEV}_{1}(\mathrm{~mL} / \mathrm{y})$ & & $-49 \pm 32 *$ & & $-78 \pm 54^{*}$ & & $-31 \pm 24$ & & $-46 \pm 30$ & & $-59 \pm 40^{*}$ & & $<.001$ \\
\hline$\Delta \mathrm{FVC}(\mathrm{mL} / \mathrm{y})$ & & $-37 \pm 32$ & & $-48 \pm 63$ & & $-24 \pm 31$ & & $-40 \pm 39$ & & $-38 \pm 49$ & & .173 \\
\hline \multicolumn{13}{|l|}{$\begin{array}{l}\text { Maximal change in } \mathrm{FEV}_{1} \\
(\Delta \text { from diagnosis to } \\
\left.\operatorname{Max}_{0-2.5}\right)\end{array}$} \\
\hline$\Delta \mathrm{FEV}_{1}(\mathrm{~mL} \#)$ & $266 \pm 365$ & & $972 \pm 899 * £ \S \|$ & & $161 \pm 252$ & & $184 \pm 239$ & & $561 \pm 459 * \S \|$ & & $<.001$ & \\
\hline
\end{tabular}

$D L_{C O}$, Diffusing capacity of the lung for carbon monoxide; ref, reference; $V A$, alveolar volume.

$* P<.05$ vs cluster 3 at corresponding time point (baseline or follow-up).

$\dagger P<.05$ to all other clusters at corresponding time point (baseline or follow-up).

$\ddagger P<.05$ vs cluster 5 at corresponding time point (baseline or follow-up).

$\S P<.05$ vs cluster 1 at corresponding time point (baseline or follow-up).

$\| P<.05$ vs cluster 4 at corresponding time point (baseline or follow-up). Paired comparison between baseline and follow-up is not shown.

Annual change in $\mathrm{FEV}_{1}$ or FVC from point of maximal lung function within $2.5 \mathrm{y}$ after start of therapy to the 12-y follow-up visit.

$\# \triangle \mathrm{FEV}_{1}$ when deducting pre-BD FEV $\mathrm{F}_{1}$ value at diagnosis from pre-BD FEV ${ }_{1}$ value at point of maximal lung function within $2.5 \mathrm{y}$ from start of therapy; reflects early response to treatment. 


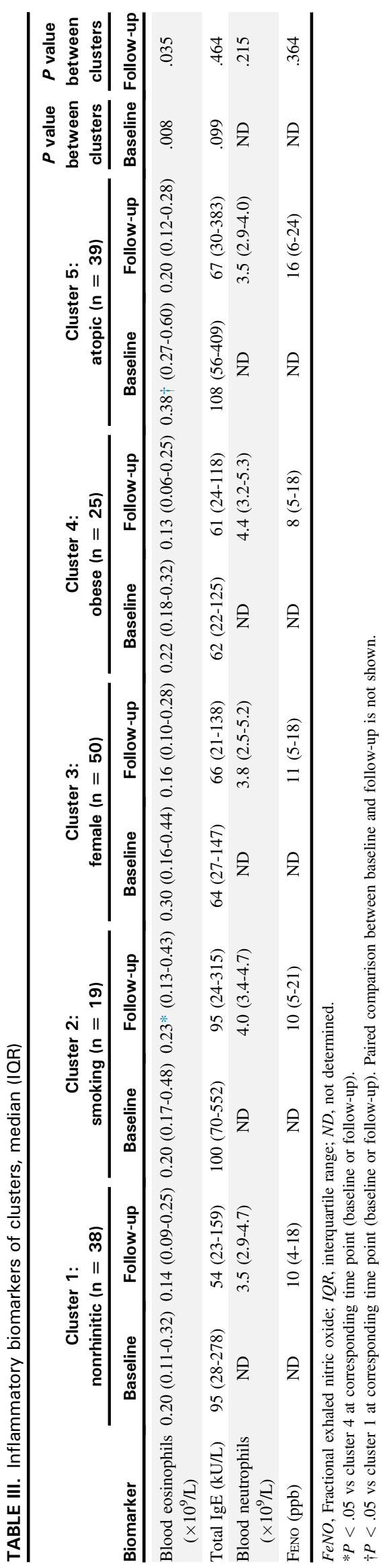

function and a wide range in the age of asthma onset. The previously defined clusters "least severe asthma with normal lung function," "middle-age onset, female-dominant," and "late-onset mild asthma" ${ }^{\prime 6,7,19}$ show resemblance to our female cluster, including predominance of nonobese females, normal lung function, ${ }^{6,7,19}$ and stable lung function in the short followups. ${ }^{6,7}$ Low smoking history, low body mass index, low count of comorbidities, and high eosinophils at diagnosis may have affected the good overall prognosis of the female cluster. However, the health care use was relatively high in this group given that many clinical parameters were within normal range. This may be explained by females' stronger perception of symptoms and lower threshold to contact health care when compared with males. ${ }^{26}$ In addition, female patients with similar severity of asthma as the corresponding male patients have shown better lung function but worse asthma-related quality of life. ${ }^{26}$ In this cluster, lung function based on spirometry was more stable when compared with lung function in other groups, but peak expiratory flow follow-up might have shown variable obstruction and disease activity. In addition, whether parameters such as blood eosinophils or airway hyperresponsiveness better correlate to disease activity and symptoms remains unclear. In the female cluster, roughly half of the patients were at fertile age, and the other half at menopausal or postmenopausal age at asthma onset, suggesting that no uniform sex hormone-related mechanism explains the pathophysiology of asthma in this cluster. However, hormonal aspects probably play a significant role in the pathogenesis and course of the disease, ${ }^{26-31}$ even though the mechanisms are likely multifactorial. Presence of symptoms at childhood in $40 \%$ of the patients also suggests the involvement of $\mathrm{T}_{\mathrm{H}}$ 2-related mechanisms and some overlap with cluster 5 .

Similar to previous findings, ${ }^{32}$ most patients in our study had a coexisting allergic or nonallergic rhinitis. However, we also identified a nonatopic mild to moderate male-predominant asthma without rhinitis, which to our knowledge has not been reported previously. Despite the second highest smoking history, $40 \%$ prevalence of permanent bronchial obstruction, and obesity at follow-up, these patients had significantly better prognosis when compared with those in clusters 2 and 4 . Rhinitis has been associated with more severe asthma, ${ }^{32,33}$ suggesting that lack of rhinitis is a significant determinant associated with the favorable prognosis in this group. Male predominance, moderate smoking history, and the highest weight gain suggest that pathophysiological mechanisms in this cluster are related to those features. Asthma in obese men has been reported to be less often severe when compared with that in obese women ${ }^{26}$ and obesity-related asthma may have important sex-specific differences concerning the mediators of the disease. ${ }^{34,35}$ For example, in a recent study, no similar difference existed in systemic inflammation between nonobese and obese males as seen in females. ${ }^{35}$ Lower level of systemic inflammation could also contribute to lesser number of comorbidities and better prognosis of asthma. Further studies are needed to evaluate the pathophysiological mechanisms in this cluster.

Cluster 5 in our study fits well with the previous findings of the important role of age of onset in defining the phenotype. ${ }^{1,3}$ Atopy, childhood symptoms, earliest onset of asthma, good steroid-responsiveness, and large $\mathrm{FEV}_{1}$ reversibility support the conclusion that this cluster represents the traditional early-onset asthma but starting at early adulthood. In addition, the good prognosis strengthens the view. ${ }^{36} \mathrm{~A}$ corresponding adult-onset 
TABLE IV. Comorbidities of clusters

\begin{tabular}{|c|c|c|c|c|c|c|c|c|c|c|c|c|}
\hline \multirow[b]{2}{*}{ Comorbidity } & \multicolumn{2}{|c|}{$\begin{array}{c}\text { Cluster 1: } \\
\text { nonrhinitic }(n=38)\end{array}$} & \multicolumn{2}{|c|}{$\begin{array}{c}\text { Cluster 2: } \\
\text { smoking ( } n=19)\end{array}$} & \multicolumn{2}{|c|}{$\begin{array}{c}\text { Cluster 3: } \\
\text { female }(n=50)\end{array}$} & \multicolumn{2}{|c|}{$\begin{array}{c}\text { Cluster 4: } \\
\text { obese }(n=25)\end{array}$} & \multicolumn{2}{|c|}{$\begin{array}{c}\text { Cluster 5: } \\
\text { atopic }(n=39)\end{array}$} & \multirow{2}{*}{$\begin{array}{c}\begin{array}{c}\boldsymbol{P} \text { value } \\
\text { between clusters }\end{array} \\
\text { Baseline }\end{array}$} & \multirow{2}{*}{$\begin{array}{c}P \text { value } \\
\text { between } \\
\text { clusters }\end{array}$} \\
\hline & Baseline & Follow-up & Baseline & Follow-up & Baseline & Follow-up & Baseline & Follow-up & Baseline & Follow-up & & \\
\hline Hypertension, n (\%) & $4(10.5)$ & $9(23.7)$ & $4(21.1)$ & $13(68.4)^{* \dagger \ddagger}$ & $3(6.0)$ & $7(14.0)$ & $12(48.0) * \dagger \ddagger$ & $19(76.0) * \dagger \ddagger$ & $2(5.1)$ & $6(15.4)$ & $<.001$ & $<.001$ \\
\hline Diabetes, n (\%) & 0 & $4(10.5)$ & 0 & $7(36.8) \dagger \dagger$ & 0 & $3(6.0)$ & $3(12.0)$ & $11(44.0)^{* \dagger \dagger}$ & 0 & $2(5.1)$ & $<.001$ & $<.001$ \\
\hline $\begin{array}{l}\text { Coronary heart } \\
\text { disease, } \mathrm{n}(\%)\end{array}$ & $1(2.6)$ & & $5(26.3) \dagger \ddagger$ & & 0 & & $2(8.0)$ & & 0 & & $<.001$ & $<.001$ \\
\hline COPD, n $(\%)$ & $2(5.4)$ & $9(23.7) \dagger$ & $8(44.4) \S$ & $10(52.6) \dagger \ddagger \|$ & 0 & $1(2.0)$ & 0 & $2(8.0)$ & $1(2.6)$ & $3(7.7)$ & $<.001$ & $<.001$ \\
\hline $\begin{array}{l}\text { Any psychiatric } \\
\text { disease, } \mathrm{n}(\%)\end{array}$ & ND & $3(7.9)$ & ND & $1(5.3)$ & ND & $5(10)$ & ND & $10(40)^{*} \dagger \ddagger$ & ND & $3(7.7)$ & ND & .001 \\
\hline Depression, $\mathrm{n}(\%)$ & ND & $1(2.6)$ & ND & $1(5.3)$ & ND & $3(6.0)$ & ND & $7(28)^{*}$ & ND & $2(5.1)$ & ND & .004 \\
\hline $\begin{array}{l}\text { Painful condition, } \\
\mathrm{n}(\%)\end{array}$ & ND & $3(7.9)$ & ND & $2(10.5)$ & ND & $2(4)$ & ND & $5(20)$ & ND & $1(2.6)$ & ND & .090 \\
\hline $\begin{array}{l}\text { Treated dyspepsia, } \\
\text { n (\%) }\end{array}$ & ND & $1(2.6)$ & ND & $2(10.5)$ & ND & $4(8)$ & ND & $6(24)$ & ND & $1(2.6)$ & ND & .020 \\
\hline $\begin{array}{l}\text { Total no. of } \\
\text { comorbidities, } \\
\text { median (IQR) }\end{array}$ & ND & $1(0-2) \ddagger$ & ND & $3(1-4)^{*} \dagger$ & ND & $0.5(0-1)$ & ND & $3(2.5-4)^{*} \dagger$ & ND & $0(0-1)$ & ND & $<.001$ \\
\hline $\begin{array}{l}\text { No. of drugs } \uparrow \text {, median } \\
\text { (IQR) }\end{array}$ & ND & $1(0-3)$ & ND & $3(2-9) * \dagger \neq$ & ND & $1(0-2)$ & ND & $6(4-7)^{*} \dagger \ddagger$ & ND & $0(0-2)$ & ND & $<.001$ \\
\hline
\end{tabular}

$I Q R$, Interquartile range; $N D$, not determined.

${ }^{*} P<.05$ vs cluster 1 at corresponding time point (baseline or follow-up).

$\dagger P<.05$ vs cluster 3 at corresponding time point (baseline or follow-up).

$\ddagger P<.05$ vs cluster 5 at corresponding time point (baseline or follow-up).

$\S P<.05$ vs all clusters at corresponding time point (baseline or follow-up).

$\| P<.05$ vs cluster 4 at corresponding time point (baseline or follow-up). Paired comparison between baseline and follow-up is not shown.

Number of drugs in use to treat comorbidities. 
A Asthma-related visits to health care
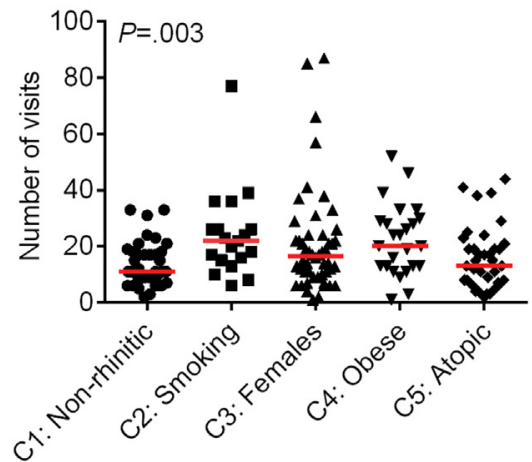

B $\geq 1$ Hospitalization due to asthma
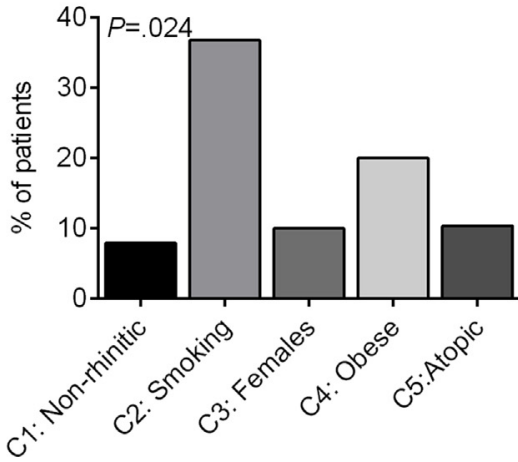

C
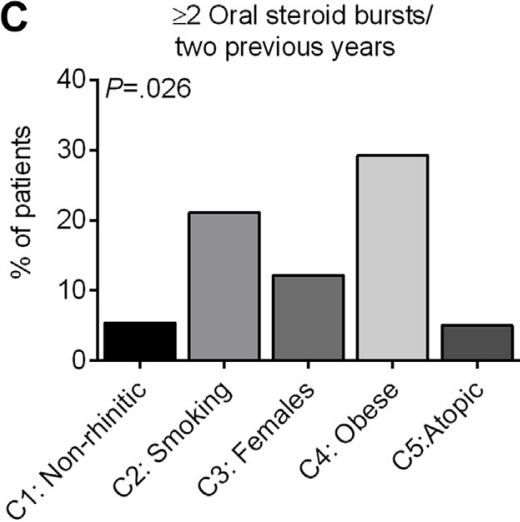

FIGURE 3. Asthma-related use of health care and use of oral steroids during the follow-up period. In A, shown is the number of asthmarelated visits to health care during the 12-year follow-up period. The red lines shown are means. In $\mathbf{B}$, shown is the proportion of patients with at least one hospitalization during the 12-year follow-up period. In $\mathrm{C}$, shown is self-reported oral steroid use within two years before the 12-year follow-up visit. In A-C, C1-C5 refers to the cluster number.
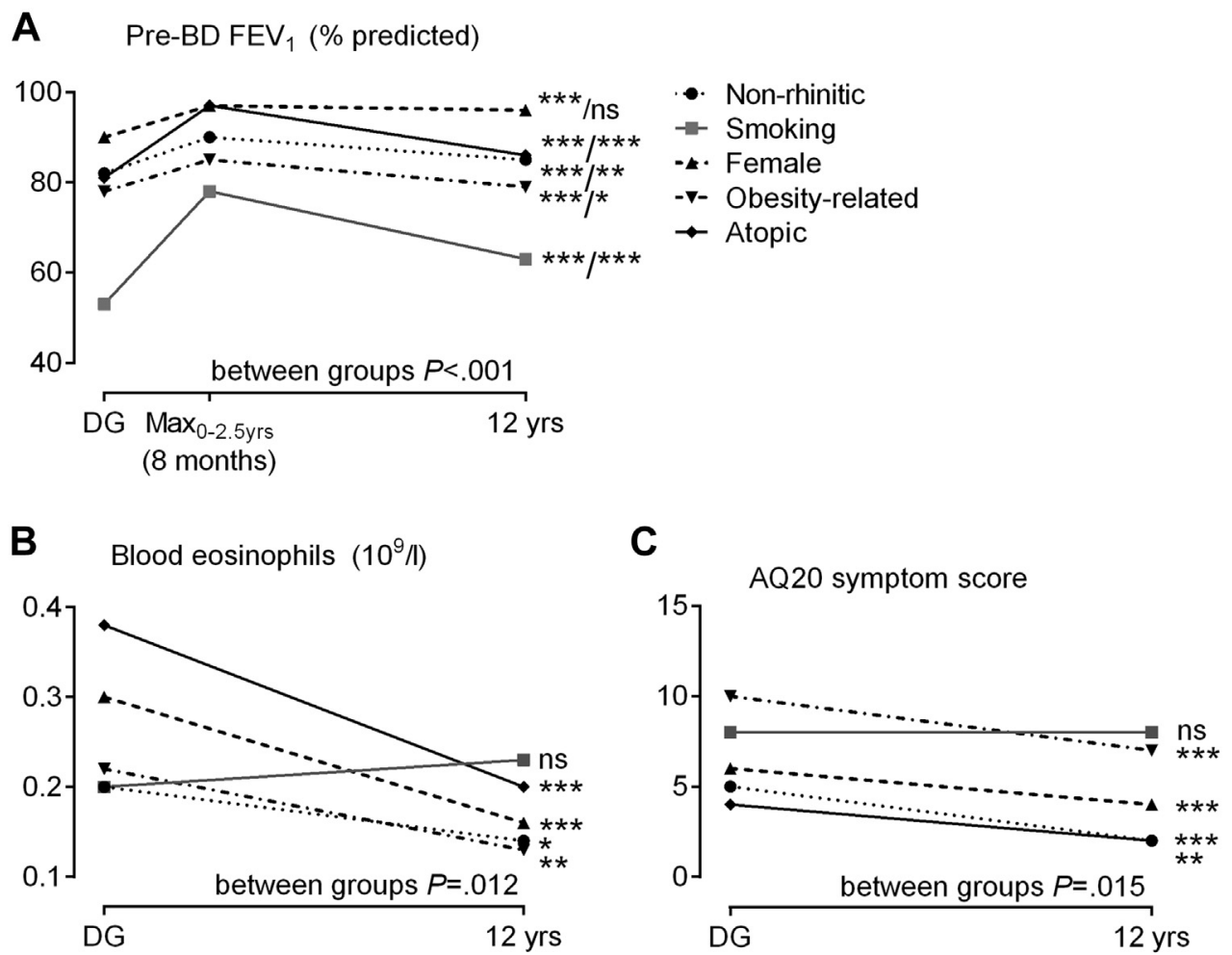

FIGURE 4. Longitudinal changes in lung function, blood eosinophils, and symptoms (AO20) in 5 clusters of adult-onset asthma. In A: ${ }^{*} P<$ $.05,{ }^{*} P<.01$, and ${ }^{*}{ }^{*} P<.001$, at left side $\Delta \mathrm{FEV}_{1}$ from diagnosis to $\mathrm{Max}_{0-2.5}$, and at right side $\Delta \mathrm{FEV}_{1}$ from Max $\mathrm{x}_{0-2.5}$ to $12-\mathrm{y}$ follow-up visit within the cluster. In B and C: ${ }^{*} P<.05,{ }^{*} P<.01$, and ${ }^{*}{ }^{*} P<.001$ of $\Delta \mathrm{FEV}$ from diagnosis to follow-up visit within each cluster.

group was recognized in the COREA study ${ }^{6}$ and many studies have recognized childhood-onset atopic asthma. ${ }^{5,7,10} \mathrm{~A}$ rather high annual lung function decline was seen after the reach of maximum point but this may be related to lung capacity because higher reversibility and higher maximal $\mathrm{FEV}_{1}$ enable higher decline in lung function. More than $70 \%$ of the patients were daily users of ICS and most were well controlled at follow-up, suggesting good compliance to treatment. Poor compliance was suspected to explain poorer outcome of early-onset asthma in a previous study. ${ }^{10}$ Because increased age has been associated with increased risk of severe asthma, ${ }^{37}$ younger age may also signifcantly contribute to the good prognosis in this group.

In 2 previous studies, an eosinophilic inflammationpredominant late-onset cluster was identified in contrast to our findings. One reason for the absence of this group may be the absence of sputum eosinophil measurements in our study and its absence as an input variable of cluster analysis, which is considered as a limitation of our study. ${ }^{2,10}$ However, use of 
TABLE V. Summary of phenotypes with their basic diagnostic characteristics, prognoses, and speculated drivers

\begin{tabular}{|c|c|c|c|c|c|}
\hline Features & Cluster 1: nonrhinitic & Cluster 2: smoking & Cluster 3: female & $\begin{array}{c}\text { Cluster 4: } \\
\text { obesity-related }\end{array}$ & $\begin{array}{c}\text { Cluster 5: } \\
\text { early-onset atopic }\end{array}$ \\
\hline Basic characteristics & $\begin{array}{c}\text { Males } 40-60 \text { y (moderate } \\
\text { smoking history) } \\
\text { and lack of rhinitis, } \\
\text { weight gain }\end{array}$ & $\begin{array}{l}\text { Older males with } \\
\text { heavy smoking } \\
\text { history }\end{array}$ & $\begin{array}{c}\text { Females } 20-60 \text { y, } \\
\text { normal } \\
\text { overweight }\end{array}$ & Older obese females & $\begin{array}{l}\text { Younger atopic } \\
\text { adults with high } \\
\text { eosinophils, may } \\
\text { have symptoms } \\
\text { in childhood }\end{array}$ \\
\hline \multicolumn{6}{|l|}{ Pre-BD FEV 1} \\
\hline Baseline & $>80 \%$ & $<60 \%$, obstruction & $>90 \%$ & $<80 \%$ & $>80 \%$ \\
\hline Follow-up & $>80 \%$ & $<70 \%$, obstruction & $>90 \%$ & $<80 \%$ & $>80 \%$ \\
\hline \multicolumn{6}{|l|}{ Symptoms } \\
\hline Baseline & Moderate & High & Moderate & High & Low \\
\hline Follow-up & Low & High & Low-moderate & High & Low \\
\hline \multicolumn{6}{|l|}{$\begin{array}{l}\text { Eosinophilic } \\
\text { inflammation }\end{array}$} \\
\hline Baseline & Moderate & Moderate & High & Moderate & High \\
\hline Follow-up & Low & Moderate-high & Low & Low & Moderate \\
\hline $\begin{array}{l}\text { Asthma control } \\
\text { at follow-up }\end{array}$ & Partially & Uncontrolled & Partially & Uncontrolled & $\begin{array}{c}\text { Controlled by low } \\
\text { steroid dose }\end{array}$ \\
\hline Comorbidities & May develop HTN, COPD & $\begin{array}{r}\text { Has/may develop HTN, } \\
\text { COPD, CHD, DM }\end{array}$ & Rarely & $\begin{array}{c}\text { Has/may develop HTN, } \\
\text { DM, PSY, CHD }\end{array}$ & Rarely \\
\hline Health care utilization & Low & High & Moderate & High & Low \\
\hline Driver related to? & Smoking, obesity & Smoking & $\begin{array}{l}\text { Sex hormones, } \\
\mathrm{T}_{\mathrm{H}} 2 \text { mechanism }\end{array}$ & $\begin{array}{r}\text { Obesity, systemic } \\
\text { inflammation }\end{array}$ & $\mathrm{T}_{\mathrm{H}} 2$ mechanism \\
\hline
\end{tabular}

$\overline{C H D}$, Coronary heart disease; $C O P D$, chronic obstructive pulmonary disease; $D M$, diabetes mellitus; $H T N$, hypertension; $P S Y$, psychiatric disease.

blood eosinophils and fractional exhaled nitric oxide is supported by a recent study showing that airway eosinophilia in adult patients can be reliably and accurately identified by blood eosinophils and fractional exhaled nitric oxide instead of induced sputum, and the accuracy is similar in different phenotypes. ${ }^{38}$ Furthermore, in the previous study, ${ }^{2}$ there was speculation on nonadherence, which might lead to persistent eosinophilia, and on overrepresentation of severe asthma because of the recruitment process. Previous studies with patients with adult-onset asthma have recognized larger groups of late-onset benign asthma, ${ }^{2,6,10}$ but our study gives a more detailed analysis of the population with mild to moderate asthma by separating it into 3 clusters (female, nonrhinitic, and atopic). Our approach reveals specific features of the prognoses of these groups that may more closely reflect the underlying pathobiology.

Our study has many strengths. Inclusion of diagnostic data gives the clinician more accurate tools to evaluate the phenotype of asthma at early phase, which helps to plan future therapy and follow-up. Wide inclusion of patients, including heavy smokers, multimorbid patients, and all severities of asthma makes our analysis clinically significant and close to real life. Limitations to this study also exist. Subjectivity cannot be avoided because variables included in factor or cluster analysis had to be selected as well as the method of cluster analysis. However, every effort was made to avoid bias due to subjectivity, for example, wide inclusion of clinical and basic variables to factor analysis and predominantly factor analysis-based selection of variables to cluster analysis. One can also argue about the small size of the cohort, being, however, comparable with many previous studies. $^{2,10}$

Altogether, we identified 5 clusters of adult-onset asthma with clinical relevance and clear basic characteristics and with 12-year prognosis (Table V). To our knowledge, this is the first study using long-term data in the construction of clusters, and is the first to succeed in identifying clusters with different disease prognoses. These results can be used in clinics to predict outcomes of patients with adult-onset asthma and to plan medication and follow-up. In addition, our results may aid in the development of personalized therapy. Even though this study concentrated on defining the clinical phenotypes, the results are encouraging when considering the possible pathobiological similarities within each cluster, being an important goal in future studies.

\section{Acknowledgements}

We are grateful to Mrs Aino Sepponen, RN, for her help through all stages of this work.

\section{REFERENCES}

1. Miranda C, Busacker A, Balzar S, Trudeau J, Wenzel SE. Distinguishing severe asthma phenotypes: role of age at onset and eosinophilic inflammation. J Allergy Clin Immunol 2004;113:101-8.

2. Amelink M, de Nijs SB, de Groot JC, van Tilburg PM, van Spiegel PI, Krouwels FH, et al. Three phenotypes of adult-onset asthma. Allergy 2013;68: 674-80.

3. Wenzel SE. Asthma phenotypes: the evolution from clinical to molecular approaches. Nat Med 2012;18:716-25.

4. Ilmarinen P, Tuomisto LE, Kankaanranta H. Phenotypes, risk factors and mechanisms of adult-onset asthma. Mediators Inflamm 2015;2015:514868.

5. Moore WC, Meyers DA, Wenzel SE, Teague WG, Li H, Li X, et al. Identification of asthma phenotypes using cluster analysis in the severe asthma research program. Am J Respir Crit Care Med 2010;181:315-23.

6. Kim TB, Jang AS, Kwon HS, Park JS, Chang YS, Cho SH, et al. Identification of asthma clusters in two independent Korean adult asthma cohorts. Eur Respir J 2013;41:1308-14.

7. Newby C, Heaney LG, Menzies-Gow A, Niven RM, Mansur A, Bucknall C, et al. Statistical cluster analysis of the British Thoracic Society Severe Refractory Asthma Registry: clinical outcomes and phenotype stability. PLoS One 2014;9:e102987. 
8. Schatz M, Hsu JW, Zeiger RS, Chen W, Dorenbaum A, Chipps BE, et al Phenotypes determined by cluster analysis in severe or difficult-to-treat asthma. J Allergy Clin Immunol 2014;133:1549-56.

9. Bourdin A, Molinari N, Vachier I, Varrin M, Marin G, Gamez AS, et al. Prognostic value of cluster analysis of severe asthma phenotypes. J Allergy Clin Immunol 2014;134:1043-50.

10. Haldar P, Pavord ID, Shaw DE, Berry MA, Thomas M, Brightling CE, et al Cluster analysis and clinical asthma phenotypes. Am J Respir Crit Care Med 2008;178:218-24.

11. Kankaanranta H, Ilmarinen P, Kankaanranta T, Tuomisto LE. Seinäjoki Adult Asthma Study (SAAS): a protocol for a 12-year real-life follow-up study of new-onset asthma diagnosed at adult age and treated in primary and specialised care. NPJ Prim Care Respir Med 2015;25:15042.

12. Tuomisto LE, Ilmarinen $P$, Niemelä $O$, Haanpää $J$, Kankaanranta $T$, Kankaanranta H. A 12-year prognosis of adult-onset asthma: Seinäjoki Adult Asthma Study. Respir Med 2016;117:223-9.

13. Miller MR, Hankinson J, Brusasco V, Burgos F, Casaburi R, Coates A, et al Standardisation of spirometry. Eur Respir J 2005;26:319-38.

14. Tommola M, Ilmarinen $\mathrm{P}$, Tuomisto LE, Haanpää J, Kankaanranta $T$, Niemelä $\mathrm{O}$, et al. The effect of smoking on lung function: a clinical study on adult-onset asthma. Eur Respir J 2016;48:1298-306.

15. Global Initiative for Asthma. From the global strategy for asthma management and prevention. Available from: www.ginasthma.org/. Accessed October 27, 2014

16. Barley EA, Quirk FH, Jones PW. Asthma health status measurement in clinical practice: validity of a new short and simple instrument. Respir Med 1998;92: 1207-14.

17. Nathan RA, Sorkness CA, Kosinski M, Schatz M, Li JT, Marcus P, et al Development of the asthma control test: a survey for assessing asthma control. J Allergy Clin Immunol 2004;113:59-65.

18. Global Initiative for Asthma; Global Initiative for Chronic Obstructive Lung Disease. Asthma, COPD and asthma-COPD overlap syndrome (ACOS). Available from: www.goldcopd.org/. Accessed April 2, 2015.

19. Kaneko Y, Masuko H, Sakamoto T, Iijima H, Naito T, Yatagai Y, et al. Asthma phenotypes in Japanese adults - their associations with the CCL5 and ADRB2 genotypes. Allergol Int 2013;62:113-21.

20. Eisner MD, Iribarren $C$. The influence of cigarette smoking on adult asthma outcomes. Nicotine Tob Res 2007;9:53-6.

21. Thomson NC, Chaudhuri R, Heaney LG, Bucknall C, Niven RM, Brightling CE, et al. Clinical outcomes and inflammatory biomarkers in current smokers and exsmokers with severe asthma. J Allergy Clin Immunol 2013;131:1008-16.

22. Kauppi P, Kupiainen H, Lindqvist A, Haahtela T, Laitinen T. Long-term smoking increases the need for acute care among asthma patients: a case control study. BMC Pulm Med 2014;14:119.

23. Kankaanranta H, Kauppi P, Tuomisto LE, Ilmarinen P. Emerging co-morbidities in adult asthma: risks, clinical associations and mechanisms. Mediators Inflamm 2016;2016:3690628
24. Boudreau M, Bacon SL, Ouellet K, Jacob A, Lavoie KL. Mediator effect of depressive symptoms on the association between BMI and asthma control in adults. Chest 2014;146:348-54.

25. Ilmarinen $\mathrm{P}$, Tuomisto LE, Niemelä $\mathrm{O}$, Danielsson $\mathrm{J}$, Haanpää $\mathrm{J}$, Kankaanranta T, et al. Co-morbidities and elevated IL-6 associate with negative outcome in adult-onset asthma. Eur Respir J 2016;48:1052-62.

26. Zein JG, Erzurum SC. Asthma is different in women. Curr Allergy Asthma Rep 2015;15:28.

27. Tan KS, McFarlane LC, Lipworth BJ. Loss of normal cyclical beta 2 adrenoceptor regulation and increased premenstrual responsiveness to adenosine monophosphate in stable female asthmatic patients. Thorax 1997; 52:608-11.

28. Triebner K, Johannessen A, Puggini L, Benediktsdottir B, Bertelsen RJ, Bifulco E, et al. Menopause as a predictor of new-onset asthma: a longitudinal Northern European population study. J Allergy Clin Immunol 2016;137:50-57. e6.

29. Troisi RJ, Speizer FE, Willett WC, Trichopoulos D, Rosner B. Menopause, postmenopausal estrogen preparations, and the risk of adult-onset asthma: a prospective cohort study. Am J Respir Crit Care Med 1995;152:1183-8.

30. Romieu I, Fabre A, Fournier A, Kauffmann F, Varraso R, Mesrine S, et al. Postmenopausal hormone therapy and asthma onset in the E3N cohort. Thorax 2010;65:292-7

31. Gomez Real F, Svanes C, Bjornsson EH, Franklin KA, Gislason D, Gislason T, et al. Hormone replacement therapy, body mass index and asthma in perimenopausal women: a cross sectional survey. Thorax 2006;61: 34-40.

32. Bousquet J, Schunemann HJ, Samolinski B, Demoly P, Baena-Cagnani CE, Bachert $C$, et al. Allergic rhinitis and its impact on asthma (ARIA): achievements in 10 years and future needs. J Allergy Clin Immunol 2012; 130:1049-62.

33. Ciprandi G, Caimmi D, Miraglia Del Giudice M, La Rosa M, Salpietro C, Marseglia GL. Recent developments in united airways disease. Allergy Asthma Immunol Res 2012;4:171-7

34. Ballantyne D, Scott H, MacDonald-Wicks L, Gibson PG, Wood L. Resistin is a predictor of asthma risk and resistin: adiponectin ratio is a negative predictor of lung function in asthma. Clin Exp Allergy 2016;46:1056-65.

35. Scott HA, Gibson PG, Garg ML, Upham JW, Wood LG. Sex hormones and systemic inflammation are modulators of the obese-asthma phenotype. Allergy 2016;71:1037-47.

36. Tuomisto LE, Ilmarinen P, Kankaanranta H. Prognosis of new-onset asthma diagnosed at adult age. Respir Med 2015;109:944-54.

37. Zein JG, Dweik RA, Comhair SA, Bleecker ER, Moore WC, Peters SP, et al. Asthma is more severe in older adults. PLoS One 2015;10:e0133490.

38. Westerhof GA, Korevaar DA, Amelink M, de Nijs SB, de Groot JC, Wang J, et al. Biomarkers to identify sputum eosinophilia in different adult asthma phenotypes. Eur Respir J 2015;46:688-96. 


\section{APPENDIX \\ Methods}

Lung function measurement, inflammatory parameters, and other clinical measures. Lung function measurements were performed with a spirometer (Vmax Encore 22, Viasys Healthcare, Palm Springs, Calif) that was calibrated daily. Post-BD measurements were taken 15 minutes after inhalation of salbutamol $(400 \mu \mathrm{g})$. Finnish reference values were used. ${ }^{\mathrm{E} 1}$ Fractional exhaled nitric oxide was measured with a portable rapid-response chemiluminescent analyzer according to the American Thoracic Society standards ${ }^{\mathrm{E} 2}$ (flow rate, $50 \mathrm{~mL} / \mathrm{s}$; NIOX System, Aerocrine, Sweden). Venous blood was collected and white blood cell differential counts were determined. Total IgE levels were measured by using ImmunoCAP (Thermo Scientific, Uppsala, Sweden). Laboratory assays were performed in an accredited laboratory (SFS-EN ISO/IEC 17025:2005 and ISO 15189:2007) of Seinäjoki Central Hospital. Patients completed the AQ20 and the ACT.

Comorbidities. Comorbidities were self-reported or based on self-reported medication, and their definitions and classifications were based on previous studies. ${ }^{\text {E3,E4 }}$ Unclear cases were confirmed from patient records. Conditions included as comorbidities were hypertension, depression, painful condition (daily use of analgesic medication), coronary heart disease, treated dyspepsia (daily medication), diabetes, thyroid disorders, rheumatoid arthritis, and other inflammatory polyarthropathies and systematic connective disorders, anxiety and other stressrelated and somatoform disorders, irritable bowel syndrome, cancer, treated constipation, stroke and transient ischemic attack, chronic kidney disease, diverticular disease of the intestine, atrial fibrillation and other cardiac arrhythmias, peripheral vascular disease, heart failure, prostate disorders, glaucoma, epilepsy, dementia, schizophrenia/nonorganic psychosis or bipolar disorder, psoriasis, inflammatory bowel disease, migraine, bronchiectasis, Parkinson disease, multiple sclerosis, viral hepatitis, and chronic liver disease. Alcohol problems, anorexia or bulimia, misuse of psychoactive substance, hearing loss, and blindness or low vision were left out because the presence of these conditions could not be assessed on the basis of patients' self-reports.

Variable selection for factor analysis and cluster analysis. Fifty-one variables from the following 3 time points were included in factor analysis: diagnosis, time of $\operatorname{Max}_{0-2.5}$, and 12-year follow-up visit. Variables included were related to lung function, reversibility, symptoms (AQ20 and ACT scores, Global Initiative for Asthma control assessment, duration of respiratory symptoms before diagnosis of asthma, and childhood respiratory symptoms), basic variables (body mass index, $\Delta$ body mass index, age of asthma onset [at asthma diagnosis], sex, and smoking), comorbidities, atopy and rhinitis, inflammatory parameters (fractional exhaled nitric oxide, blood eosinophils, blood neutrophils, and total IgE), diffusing capacity, workrelated asthma (defined by the question "Does your asthma aggravate during working day?”), aspirin-sensitive asthma, and ACOS. Use of medication (ICS dose and asthma medication) and health care use were included as composite variables. The composite variable constructed on the basis of the use of asthma medication was the following: $1=$ only short-acting $\beta_{2}$ agonist when needed, 2 = daily ICS, 3 = daily ICS and one add-on drug, $4=$ daily ICS and more than 1 add-on drug, and $5=$ daily ICS and oral steroid and/or omalizumab. Use of the health care composite variable was scaled on the basis of frequency of visits to the emergency department, oral corticosteroid courses, or absence from school or work (at least 1 of these): $1=$ none, $2=$ less than once a year, $3=$ once a year, and $4=$ more than once a year.

When choosing variables for cluster analysis, the variable with the highest loading was selected from each factor with an eigenvalue higher than 1.2 with few exceptions (Table E2). Logarithmic transformations were carried out for continuous variables when applicable. Categorical variables were converted into binary $(0 / 1)$ variables. All variables were converted into $z$ scores for cluster analysis. 
TABLE E1. Diagnostic criteria fulfilled by each cluster*

\begin{tabular}{|c|c|c|c|c|c|c|}
\hline Diagnostic criteria fulfilled & Cluster 1 & Cluster 2 & Cluster 3 & Cluster 4 & Cluster 5 & $P$ value \\
\hline $\begin{array}{l}\text { Positive BD effect on } \mathrm{FEV}_{1}(\geq 15 \% \text { and } 200 \\
\mathrm{mL}) \text { at least in } 1 \text { spirometric measurement, } \\
\mathrm{n}(\%)\end{array}$ & $7(18.4)$ & $8(42.1)$ & $10(20.0)$ & $7(28.0)$ & $17(43.6)$ & .045 \\
\hline $\begin{array}{l}\text { If not } \\
\text { Diurnal variability }(\geq 20 \%) \text { or repeated } \\
\text { reversibility }(\geq 15 \% / 60 \mathrm{~L} / \mathrm{min}) \text { in PEF } \\
\text { follow-up, } \mathrm{n}(\%)\end{array}$ & $25(65.8)$ & $9(47.4)$ & $35(70.0)$ & $16(64.0)$ & $18(46.2)$ & .127 \\
\hline $\begin{array}{l}\text { If not } \\
\text { Variable bronchial obstruction shown in } \\
\text { exercise, allergen exposure, or as a steroid } \\
\text { treatment response, } \mathrm{n}(\%)\end{array}$ & $6(15.8)$ & $2(10.5)$ & $5(10.0)$ & $2(8.0)$ & $4(10.3)$ & .881 \\
\hline Total, n (\%) & 38 (100) & 19 (100) & $50(100)$ & $25(100)$ & 39 (100) & \\
\hline
\end{tabular}

$P E F$, Peak expiratory flow.

*Practically all patients underwent 1 or more spirometric evaluations and a 2-wk PEF follow-up. Other tests were performed if considered necessary. Only the major diagnostic feature per patient is shown using a hierarchical evaluation in which positive BD response on $\mathrm{FEV}_{1}$ was considered first, if negative, and then PEF changes were considered, and if negative, the other tests were considered.

TABLE E2. Identified factors $1-15$ in factor analysis (factor names are representative of pattern of loading)

\begin{tabular}{|c|c|c|}
\hline & & \\
\hline 1. Lung function & Pre-BD FVC at follow-up & Pre-BD FEV 1 at follow-up* \\
\hline 2. Obstruction & Post-BD $\mathrm{FEV}_{1} / \mathrm{FVC}$ at diagnosis & \\
\hline 3. Smoking & Smoking status at diagnosis (current/ex/never) & Pack-years at follow-up $\dagger$ \\
\hline 4. Symptoms of asthma & ACT score at follow-up & \\
\hline 5. Age and comorbidities & $\begin{array}{l}\text { Number of other than asthma/allergy-related drugs in } \\
\text { use at follow-up }\end{array}$ & \\
\hline 6. $\mathrm{FEV}_{1}$ reversibility at follow-up & $\mathrm{FEV}_{1}$ reversibility at follow-up & \\
\hline 7. $\mathrm{FEV}_{1}$ reversibility at diagnosis & $\mathrm{FEV}_{1}$ reversibility at diagnosis & \\
\hline 8. Obesity & BMI at follow-up & \\
\hline 9. Maximal response to treatment & $\begin{array}{l}\text { Maximal response in } \mathrm{FEV}_{1} \text { (from diagnosis } \\
\text { to } \mathrm{Max}_{0-2.5} \text { ) }\end{array}$ & \\
\hline 10. Work-related asthma & $\begin{array}{l}\text { "Does your asthma aggravate during working day?" } \\
\text { at follow-up (yes/no) }\end{array}$ & GINA: Limitation of activities (none/any) $\ddagger$ \\
\hline 11. Neutrophilic inflammation & Blood neutrophils at follow-up & \\
\hline 12. Symptoms of asthma $<16$ y & $\begin{array}{l}\text { "Did you have respiratory symptoms suggesting } \\
\text { asthma during childhood }(<16 \text { y) even though } \\
\text { asthma had not been diagnosed?" (yes/no) }\end{array}$ & \\
\hline 13. Rhinitis and atopy & Rhinitis at follow-up (yes/no) & \\
\hline 14. Eosinophilic inflammation & FENO at follow-up & Blood eosinophils at follow-up $\ddagger$ \\
\hline $\begin{array}{l}\text { 15. Symptoms of asthma before } \\
\text { diagnosis }\end{array}$ & Duration of respiratory symptoms before diagnosis & \\
\hline Outside factor analysis & & Age at asthma onset $\S$ \\
\hline Outside factor analysis & & $\operatorname{Sex} \S$ \\
\hline
\end{tabular}

BMI, Body mass index; FENO, fractional exhaled nitric oxide; GINA, Global Initiative for Asthma.

*Factor included many variables with close to similar loading, selected because of clinical aspects.

$\dagger$ Selected because of technical aspects.

$\ddagger$ Variable with the second highest loading was selected because of missing values in the variable with the highest loading.

$\S$ Included as basic variables. 
TABLE E3. Patient characteristics of the study cohort $(n=171)$ at baseline and follow-up visit

\begin{tabular}{|c|c|c|c|}
\hline Characteristic & At diagnosis & At follow-up & $P$ value \\
\hline Females, n (\%) & $100(58.5)$ & $100(58.5)$ & \\
\hline Age $(y)$, mean $\pm S D$ & $45.7 \pm 13.7$ & $58.0 \pm 13.7$ & \\
\hline BMI, median (IQR) & $26.9(23.8-30.0)$ & $28.1(24.3-31.3)$ & $<.001$ \\
\hline Current/ex-smokers, n (\%) & $82(48.0)$ & $85(49.7)$ & .250 \\
\hline Pack-years, median (IQR) & $11(4-20)$ & $15(5-27)$ & $<.001$ \\
\hline Uncontrolled asthma, n (\%) & ND & $47(27.5)$ & \\
\hline Atopic, $\mathrm{n}(\%)$ & $57(36.5)$ & ND & \\
\hline Rhinitis, n (\%) & ND & $121(70.8)$ & \\
\hline Blood eosinophils $\left(10^{9} / \mathrm{L}\right)$, median (IQR) & $0.30(0.18-0.42)$ & $0.17(0.10-0.27)$ & $<.001$ \\
\hline Daily ICS users, n (\%) & $12(7.1)$ & $135(78.9)$ & $<.001$ \\
\hline $\begin{array}{l}\text { ICS starting/daily dose ( } \mu \mathrm{g} \text { budesonide } \\
\text { equivalents), median (IQR) }\end{array}$ & $800(800-1000)$ & $800(400-1000)$ & $<.001$ \\
\hline Pre-BD FEV ${ }_{1}(\%$ predicted $)$, mean $\pm \mathrm{SD}$ & $80 \pm 18$ & $85 \pm 17$ & $<.001$ \\
\hline Post-BD FEV $1 / \mathrm{FVC}$ (ratio), median (IQR) & $0.79(0.74-0.83)$ & $0.75(0.69-0.80)$ & $<.001$ \\
\hline AQ20 (no. of YES), median (IQR) & $6(4-10)$ & $4(1-7)$ & $<.001$ \\
\hline ACT score, median (IQR) & ND & $22(19-24)$ & \\
\hline
\end{tabular}

$B M I$, Body mass index; $N D$, not determined.

Note. Statistical analyses were performed by paired-samples $t$ test, related-samples Wilcoxon signed rank test, or McNemar test.

\section{REFERENCES}

E1. Viljanen AA, Halttunen PK, Kreus KE, Viljanen BC. Spirometric studies in non-smoking, healthy adults. Scand J Clin Lab Invest Suppl 1982;159:5-20.

E2. American Thoracic Society; European Respiratory Society. ATS/ERS recommendations for standardized procedures for the online and offline measurement of exhaled lower respiratory nitric oxide and nasal nitric oxide, 2005. Am J Respir Crit Care Med 2005;171:912-30.
E3. Barnett K, Mercer SW, Norbury M, Watt G, Wyke S, Guthrie B. Epidemiology of multimorbidity and implications for health care, research, and medical education: a cross-sectional study. Lancet 2012; 380:37-43.

E4. Ilmarinen P, Tuomisto LE, Niemelä O, Danielsson J, Haanpää J, Kankaanranta T, et al. Co-morbidities and elevated IL-6 associate with negative outcome in adultonset asthma. Eur Respir J 2016;48:1052-62. 